Article

\title{
A study on vocabulary learning strategies employed by English major students at Ho Chi Minh City University Of Food Industry
}

Quynh, Tran Thi Nhu $1^{*}$

1 Ho Chi Minh City University of Food Industry; quynhnhutran2510@gmail.com
* Correspondence: quynhhhutran2510@gmail.com

Abstract: Vocabulary is extremely important for language learners. They will face difficulties learning a foreign language if their vocabulary knowledge is insufficient. The goal of this study is to find out which vocabulary learning strategies were used the most by third-year English majors and whether gender influenced their choice of vocabulary learning strategies. The participants are sixty-one English major students from Ho Chi Minh City University of Food Industry, fifty-three of whom are female and eight of whom are male. The questionnaire is the testing tool, and it is divided into five categories: determination strategies, cognitive strategies, memory strategies, metacognitive strategies and social strategies. The findings indicate that participants favoured guessing the meaning from context and making a list of words and memorizing the most, while social tactics were the least common. Furthermore, gender has little impact on the preference of vocabulary learning techniques.

Citation: Quynh, T. T. N. https://doi.org/10.3390/xxxxx

Academic Editor: Quynh, Tran Thi Nhu.

Received: date

Accepted: date

Published: date

Publisher's Note: MDPI stays neutral with regard to jurisdictional claims in published maps and institutional affiliations.

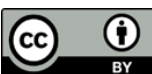

Copyright: (c) 2021 by the authors. Submitted for possible open access publication under the terms and conditions of the Creative Commons Attribution (CC BY) license (https://creativecommons.org/license s/by/4.0/).
Keywords: strategies; English major.

\section{Introduction}

Vocabulary is important for learning a foreign language. Vocabulary, according to (Nation, 2001), is the basis for learning four language skills: hearing, communicating, reading, and writing. Furthermore, (Astika, 2016) cites Mc-Cathy as saying that substantive conversation can not take place without a proper awareness of vocabulary. Academics demonstrate that lexical impairment frequently interferes with everyday contact. Acquiring vocabulary can help learners understand what others mean. Language learners who have a small vocabulary are unable to use a foreign language efficiently. It is undeniable that expanding one's vocabulary is critical for language learners in general, and English majors at Ho Chi Minh City University Of Food Industry in particular. Learners must use appropriate preparation techniques to increase their language buildup. Identifying appropriate 
vocabulary techniques is especially important for third-year English majors who want to study specialized subjects such as scholarly writing, translation, interpretation, and research methodology. Many scholars have conducted studies on vocabulary learning methods in recent years. In this study, we want to look at which vocabulary learning language learners choose and how gender influences their choices.

\section{Literature review}

2.1 Definitions of learning strategies

Learning strategies have been defined by some authors as follows: Chamot (2005) says that learning strategies consist of approaches, techniques and actions taken by students to encourage the learning and acquire linguistic information. According to Rubin ( 1987), learning strategies are those developed by learners and those strategies that affect their learning directly, while Oxford (1990) claims that learning strategies are used by learners to help their language learning become more successful, self-directed and enjoyable.

\subsection{Classifications of vocabulary learning strategies}

Oxford (Language learning strategies, 1990) divides vocabulary learning strategies into two types: direct and indirect strategies. Direct strategies include memory, emotional, and reward strategies, while indirect strategies include metacognitive, emotional, and affective strategies. Schmitt (1997) expanded on Oxford's theories by introducing exploration and consolidation methods. Determination strategies and social strategies are two types of discovery strategies. Consolidation techniques include recall strategies, cognitive strategies, and metacognitive strategies. Some scholars have a clear overview of these methods. Schmitt and McCarthy (1997) state that learners use determination tactics to discover the significance of a new word without the help of another individual. According to Kramsch (1979), social techniques depict learners' experiences with others while learning a new expression. Students should use these exercises to study and practice vocabulary in groups, then ask teachers to review their work for consistency. Many scholars have looked at the vocabulary learning methods used by language learners. Dinh (Hằng, 2008) examines five types of vocabulary learning strategies: determination, memory, cognitive, metacognitive, and social. Le (Hương, 2018) relies on an almost identical range of tactics, but with the inclusion of device-assisted strategies rather than social strategies. In addition, Hashemi Hadavi (Hashemi \& Hadavi, 2015) discussed eight vocabulary learning techniques, including dictionary, guessing, research interests, recall, autonomy, notetaking, selective attention, and social strategies. In the same vein, Manuel (2017) and Aravind \& Rajasekaran (2018) investigate the same strategies: determination, 
memory, cognitive, metacognitive, and social strategies. Similarly, Astika (2016) surveys only four strategies: cognitive, metacognitive, memory, and determination strategies.

The taxonomy established by Schmitt (1997) was used for the purposes of this research. Schmitt suggests two methods for vocabulary instruction. There are two types of techniques: exploration strategies and consolidation strategies. Discovery techniques are used to help the learner discover the meaning of terms introduced to him/her for the first time, while convergence strategies are used to help the learner internalize the meaning as he/she hears the word again later. These strategies are further subdivided into five groups, such as determination strategies (DET), which correspond to human learning strategies that assist learners in discovering the meaning of words without the assistance of teachers or peers. Memory strategies (MEM) engage learners in understanding the newly learned word by applying their existing or contextual information to the new word, while social strategies (SOC) engage learners in contact with others. Cognitive strategies (COG), in which learners indulge in more mechanical thinking rather than behavioral processing, and metacognitive (MET) strategies, in which learners engage in processes such as decision-making, tracking, and assessing learner development. The following experiments looked at how students use vocabulary learning techniques. Gu and Johnson (1996) (1996) used a long questionnaire in their research to determine which techniques Chinese university students use to acquire English vocabulary. They discovered that the use of retention techniques was associated with higher vocabulary size but not with language proficiency after correlating the findings with tests of vocabulary size and language proficiency. Still, Schmitt (1997) discovered that the most commonly used techniques in a study of 600 high schools, colleges, and adult learners in Japan were dictionary use, oral and written repetition, word spelling, and contextual guessing, while semantic chart, the main word system, and first language cognates were used less frequently. It was to prove that more capable learners were slanted to utilize more complex and meaning-centered procedures than less capable learners. The descriptive survey method was used to investigate the vocabulary learning strategies used by third-year English majors and the effect of gender on their choice of vocabulary learning strategies.

\section{Materials and Methods}

\subsection{Research design}

The descriptive survey method was used to investigate the vocabulary learning strategies used by third-year English majors and the effect of gender on their choice of vocabulary learning strategies. 
3.2 Participants of the study

Sixty-one third-year English major students of Ho Chi Minh City University of Food Industry were included in this study, including fifty-three females and eight males. The significant difference in the numbers of males and females is due to the dominance of female students over male students in English language learning.

\subsection{Instrument}

The current study used a questionnaire derived from Schmitt's (1997) taxonomy of vocabulary learning techniques to determine the vocabulary learning techniques that the participants used (see Appendix). Determination strategies, cognitive strategies, memory strategies, metacognitive techniques and social strategies were among the five areas addressed by the questionnaire.

\subsection{Procedures}

The survey was sent out on May 4, 2021. Students were informed that their participation in the survey was completely voluntary before they began. They were also instructed to respond as truthfully as possible. The questionnaire was not translated into Vietnamese because all of the participants were English majors. The poll was kept anonymous to avoid participants answering in a way that they thought the researchers would appreciate. The participants were asked if they employed any specific strategies.

\section{Results}

Descriptive statistics are used to identify the most and least often utilized vocabulary acquisition methods. Table 1.1 (below) shows the findings of the descriptive analysis. As seen in the table, the most commonly utilized vocabulary 100 learning tactics are determination techniques, followed by cognitive strategies, memory strategies, metacognitive techniques, and social strategies.

4.1. Descriptive statistics for each vocabulary learning strategy

\begin{tabular}{||c||c|c||}
\hline \multicolumn{1}{|c||}{ Description } & Strategy Categories & Rank \\
\hline \hline I guess the meaning from context & Determination & \\
\hline \hline I consult a monolingual dictionary & Strategy(DET) & \\
\hline \hline I analyze the parts of speech & & 2 \\
\hline \hline I make a list of words and memorize & & \\
\hline
\end{tabular}




\begin{tabular}{||c||c||c||}
\hline \multicolumn{1}{|c||}{ I repeat the word verbally } & Cognitive & \\
\hline \hline I put English labels for physical objects & Strategy(COG) & 3 \\
\hline \hline I study the sound of the words & Memory & \\
\hline \hline I remember word initial letter & Strategy(MEM) & \\
\hline \hline I use flashcards & Metacognitive & \\
\hline \hline I skip or pass the new word & Strategy(MET) & \\
\hline \hline I ask my teacher for making a sentence & Social Strategy(SOC) \\
\hline \hline I ask my teacher for LI strategy & \\
\hline
\end{tabular}

Table 1. Descriptive statistics for each vocabulary learning strategy

\subsubsection{Determination strategy}

As presented in Table 1, the most commonly utilized vocabulary learning tactics are "I guess the meaning from context",

\subsubsection{Cognitive strategy}

The most commonly utilized vocabulary learning tactics are "I make a list of words and memorize", followed by "I repeat the word verbally" and "I put English labels for physical objects", as ranked by students. Language learners' favorite tactics for vocabulary building, according to Schmitt (Vocabulary: Description, Acquisition and Pedagogy. Vocabulary learning strategies, 1997), include repeating lexical items aloud, verbal and written repetition of terms, and taking notes in class. According to Oxford (1990), some of these tactics include analyzing, writing, and summarizing. According to Oxford (Language learning strategies, 1990) these strategies "enable learners to understand and produce new languages by many different means".

\subsubsection{Memory strategy}

Memory, according to Benkhenafou (2015), refers to the methods through which students employ images or groups to help them identify a new term with things they already know. The most commonly utilized vocabulary 
efficient ways of learning new lexical elements. Memory methods include mental tactics such as categorizing words into elements of speech such as nouns and verbs, as well as synonyms and antonyms, to envisage a circumstance in which the word may be employed. Nation (2005) presents a set of criteria for knowing a word, including its meaning, usage, and form. Word form knowledge is the understanding of a word's parts, spelling, and sound. The grammatical features of the term, such as parts of speech and word collocation, are included in word use knowledge. Regarding word meaning, knowledge refers to the concept of the word, what it refers to, and which words can be associated with it. Using memory methods, you may compile this collection of word knowledge. Knowledge refers to the concept of the word, what it refers to, and which words can be associated with it. This collection of word knowledge can be compiled using memory methods.

\subsubsection{Metacognitive strategy}

The metacognitive strategies used by the participants to learn and expand their vocabulary knowledge. The most commonly utilized vocabulary learning tactics are "I use flashcards", followed by "I skip or pass the new word".

\subsubsection{Social strategy}

According to Schmitt, social methods entail learners interacting with others in order to discover the meaning of words. The most commonly utilized vocabulary learning tactics are "I ask my teacher for making a sentence", followed by "I ask my teacher for LI strategy". These practices are employed in classes, implying that the participants' learning processes are highly reliant on the language teachers. As Laufer \& Hulstijn (Incidental vocabulary acquisition in a second language: The construct of task-induced involvement, 2001) define it, this type of vocabulary acquisition is known as direct or explicit vocabulary acquisition. This method of vocabulary acquisition is known as conscious learning; language learners learn vocabulary by deciphering the meaning of words in isolation or in context. Language teachers can assist language learners in using direct or explicit vocabulary acquisition by offering matched translation equivalents and synonyms for the words.

4.2. The most and least-reported vocabulary learning strategies

\begin{tabular}{|l|c|c|}
\hline Description & $\begin{array}{l}\text { Number of } \\
\text { choices }\end{array}$ & Percentation \\
\hline I make a list of words and memorize (COG) & 30 & $49.2 \%$ \\
\hline
\end{tabular}




\begin{tabular}{|l|c|c|}
\hline I guess the meaning from context (DET) & 29 & $47.5 \%$ \\
\hline I repeat the word verbally (COG) & 28 & $45.9 \%$ \\
\hline I study the sound of the words (MEM) & 28 & $45.9 \%$ \\
\hline I consult a monolingual dictionary (DET) & 24 & $39.3 \%$ \\
\hline I analyze the parts of speech (DET) & 24 & $39.3 \%$ \\
\hline I use flashcards (MET) & 21 & $34.4 \%$ \\
\hline I ask the teacher for make a sentence (SOC) & 15 & $24.6 \%$ \\
\hline I put English labels for physical objects (COG) & 14 & $23 \%$ \\
\hline I remember word initial letter (MEM) & 12 & $19.7 \%$ \\
\hline I ask my teacher for LI strategy (SOC) & 8 & $13.1 \%$ \\
\hline I skip or pass the new word (MET) & 7 & $11.5 \%$ \\
\hline
\end{tabular}

Table 2. The most and least-reported vocabulary learning strategies

When it comes to the most and the least frequently used vocabulary learning strategies with respect to individual items,

Table 4.2 shows that the most common usage was "I make a list of words and memorize" with 30/61 (49.2\%), followed

\begin{tabular}{|l|c|}
\hline \multicolumn{1}{|c|}{ Vocabulary retention methods } & Percentage \\
\hline Look up vocabulary in assigned groups & $18 \%$ \\
\hline Small dictionaries after each PracticeBook & $4.9 \%$ \\
\hline
\end{tabular}




\begin{tabular}{|l|c|}
\hline Teacher explains each word using pictures (using powerpoint) & $26.2 \%$ \\
\hline At the end of each lesson, teacher reviews learned vocabulary, & $40.9 \%$ \\
organized vocabulary games & \\
\hline
\end{tabular}

Table 3. Vocabulary retention methods

Determination Techniques were identified as the most frequently-used strategy among the five vocabulary acquisition strategies based on Schmitt's taxonomy, followed by Cognitive Strategies as the second most frequently-used strategy, and Memory Strategies as the third most frequently-used strategy. Social Strategies were the least often used strategy, and Metacognitive Strategies were the fourth most commonly used strategy. The most likely reason for this problem is that language study is viewed as a solitary or asocial activity. As a result, pupils are hesitant to seek help from others while learning new terms. 
According to the findings of the current study, the most favoured methods were guessing from context and making a

list of words and memorizing, which were used by 47.5 percent and 49.2 percent of the respondents, respectively, and according to the data. This viewpoint is consistent with Schmitt's (1997) notion that more advanced students utilize more complicated and meaning-focused methods than less advanced students.

\section{Conclusions}

This study investigated the most and least frequently used strategies for vocabulary learning strategies by English strategies were the least popular. Similarly, the Nation believes that explicit education of strategies can increase learners' strategic understanding. Learner autonomy is also a result of strategy training. In terms of gender differences in vocabulary acquisition processes. Gender differences in vocabulary acquisition procedures were shown to have no effect. As a consequence of the study's findings, instructors will have access to a range of vocabulary learning techniques to widen their vocabulary learning sources, and students will be more aware of the value of vocabulary learning techniques in language learning and teaching.

\section{Patents}

Funding: Please add: This research received no external funding.

Conflicts of Interest: The authors declare no conflict of interest.

\section{References}

1. Astika. (2016). Vocabulary learning strategies of secondary school students.

2. B, A., \& V., R. (2018). A study on vocabulary learning strategies of rescarch scholars.

3. Chamot. (2005). Language learning strategy instruction.

4. Gu, \& Johnson. (1996). Vocabulary learning strategies and language learning outcomes.

5. Hashemi, \& Hadavi. (2015). Investigation of vocabulary learning strategies among EFL Iranian medical sciences students.

6. Hằng, Đ. T. (2008). Vocabulary learning strategies employed by students at Hung Vuong Gifted High School. ULIS.

7. HH, B. (2015). Memory strategies: boosting cabulary learning and learner autonomy.

8. Hương, L. P. (2018). A survey study on academic vocabulary learning strategies by EFL university students.

9. Kramsch. (1979). Word watching: Learning vocabulary becomes a hobby. Foreign Language Annals.

10. Laufer, B., \& Hulstijn, J. (2001). Incidental vocabulary acquisition in a second language: The construct of task-induced involvement.

11. Manuel. (2017). Evaluating Vocabulary Learning Strate- gies (VLS): Gender differences, the most and least used (VLS) among Angolan EFL Students at the Fac- ulty of Arts. . Luanda, Angola: International Journal of Scientific Research in Education.

12. N, S. (1997). Vocabulary: Description, Acquisition and Pedagogy. Vocabulary learning strategies. Cambridge University.

13. Nation. (2001). Learning vocabulary in another language.

14. Nation, P. (2005). Teaching and learning vocabulary. . New Jersey: Lawrence Erlbaum.

15. Oxford. (1990). Language learning strategies. Boston: Newbury House. 
16. Oxford, \& Nyikos. (1989). Variables affecting choice of language learning strategies by university students. The modern language journal.

17. Oxford, R. (1990). Language learning strategies: What every teacher should know. New York.

18. Rubin. (1987). Learner strategies.

19. Schmitt, \& McCarthy. (1997). Vocabulary: Description, acquisition and pedagogy. Cambridge University.

20. Schmitt, N. (1997). Vocabulary learning strategies. . Cambridge: Cambridge University Press. 